\title{
EduCATIONAL Digital Games as LEARNing TOOLS: MiCROSOFT KODU's CASE
}

\author{
Christos Lalos ${ }^{1}$ and Ilektra Skarpa ${ }^{2}$ \\ ${ }^{1}$ IT Educator, PhD Candidate at University of Alicante in Spain \\ ${ }^{2}$ Primary School Teacher, PhD Candidate at University of Murcia in Spain
}

\begin{abstract}
The virtual environments of electronic games and, in general, digital media engagement undoubtedly attract the interest of young people in your days. On the other hand, students in schools seem to enjoy the traditional educational process. Students, therefore, need to be motivated to participate in school lessons, and a way to achieve this, is to use new digital media that are considered particularly popular with young people. The main objective of the project is to propose a didactic approach to achieving some of the objectives of the courses in the Primary School. In particular, an educational game is presented and developed as an example, with the help of Microsoft Kodu digital software, and it is recorded how it works as a learning tool.
\end{abstract}

\section{KEYWORDS}

Electronic communities, digital game, educational software, Microsoft Kodu

\section{INTRODUCTION}

In 2009, Microsoft introduced a tool that anyone could use to easily and quickly program their own simple game. Who does not remember Sparrow, an 11-year-old girl who in front of the astonished eyes of the public, made in a few minutes a simple game that she could play with the manager of Microsoft? So according to the description of the title by the company itself, it is more of a programming language that uses the gamepad to enter commands, than a game in which users create tracks and content.

Nowadays, despite advances in technology and research on new methods of approaching the educational process, the way in which lessons are taught in schools, most of the time, remains static and is based on the lecture-examination model. This teacher-centered approach does not place the learner at the center of the educational process, resulting in the latter losing interest in learning and ending up memorizing concepts with the sole motive of scoring their performance.

It is often heard by many people, the requirement that learning should become more attractive or even fun. This implies that children do not enjoy learning. However, many research findings contradict this hypothesis, showing that children enjoy learning when it is relevant and appropriate and when they have a sense of progress. There is a need, therefore, for the teaching of courses, for the integration of activities that are in line with the interests and preferences of young students and which will be based on scientific studies but also organized in structured social contexts.

Virtual electronic gaming environments and digital engagement in general are unquestionably attracting young people's interest. On the other hand, students in schools do not seem to enjoy the traditional educational process. Students, therefore, need to be motivated to participate in 
school activities, and the way to achieve this is to use new digital tools that are particularly popular with young people. The main objective of this paper is to propose a didactic approach to achieve some of the objectives of the courses in Primary School. Specifically, an educational game is presented and developed as an example, with the help of digital Microsoft Kodu software, and it is recorded how it works as a learning tool.

\section{INFORMATION AND COMMUNICATION TEChNOLOGIES (I.C.T.) IN EDUCATION}

In today's society, demands and needs change significantly due to the evolution of technology and economy. Consequently, in every area of everyday life, there is a need to adapt to this new reality. Education could not be absent from this general adjustment. Efforts are being made to integrate innovation in this area, and on this basis many pre-school education programs, mainly in developed countries, incorporate the use of Information and Communication Technologies (I.C.T.). At the same time, the international literature shows the positive effects of I.C.T., when they function as complementary tools of other educational activities, in the learning of young children (Kó $\mu\rceil \zeta, 2004)$. It is an educational orientation according to which computational technology is at the service of the student either as a tool for building his knowledge or as a mediator for social interaction and collaboration between students. Education in Informatics and I.C.T., through the critical processing of the received information, is a valuable tool for the acquisition of rich cultural and scientific knowledge, to ensure lifelong learning and to promote individualized education. It also contributes to the improvement of the education provided to individuals with special educational needs in the regular school classroom or in properly organized and staffed integration classes. At the same time, the foundations are being laid for the substantial connection of education in the labor market, which will lead in the future, among other things, to development at the individual and social level (Greek I.C.T. Curriculum).

I.C.T. is a field of application of various scientific categories, which has shown rapid growth, in the context of the general technological progress of the last twenty years. The most specific study of the integration of I.C.T. in activities of daily life, develops into an extremely popular field of interest, as the positive results of their applications in the economy and society (www.sidsete.gr)

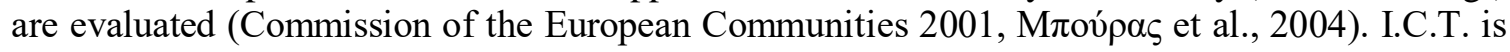
another interdisciplinary subject, which draws on payments from the fields of Informatics and Telecommunications. It mainly deals with the management and processing of information as well as the promotion of communication of a process, which requires the use of computers, software and telecommunications devices, conversion, storage, protection, processing, transmission and retrieval of information.

The term "educational software" refers to all the applications for computers or the global web that serve educational purposes. Some software helps teachers by facilitating their work.

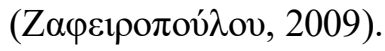

Other times, they reinforce the student's effort by providing them with practice tools, knowledge sources, and more. In addition, there is educational software used in the coordination of the educational project, the collection and organization of the educational material, the training and observance of the educational program and, more generally, the administration and operation of an educational organization. In addition to the software that is used in the service of the teacher and the education system, there is also educational software adapted to the specifics of the learner. Thus, distance education systems are quite common, while advanced self-education systems have begun to operate, either remotely or with the help of an educational organization. Educational software can be considered any organized source of knowledge, such as electronic 
libraries, encyclopedias, digital collections of audiovisual material, etc. Finally, there are several electronic games with a purely educational character.

In advanced countries there is software used in education since the middle of the last century. Initially, the software served more to teach technology and computer science, but gradually programs began to appear for a variety of other educational purposes. Today, there is specialized educational software for the teaching of several thematic units, such as foreign languages, mathematics, physics, computer science, etc. These programs serve a variety of needs, from teaching young children to teaching at the university level. Unfortunately, very few of them are

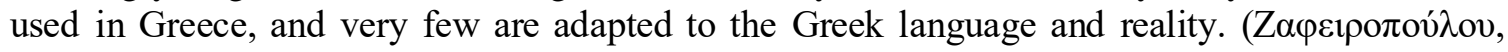
2009).

\section{Microsoft KodU}

According to Wikipedia (Microsoft Kodu Game Lab) "Microsoft Kodu, originally called Boku, is a comprehensive program development environment created in Microsoft's FUSE laboratories. It runs on Xbox and all Microsoft operating systems (Windows XP, Windows Vista, Windows 7, Windows 8). It was first released for Xbox on 30/06/2009. Versions for all Microsoft operating systems have since been released.

Microsoft Kodu is a visual programming tool built on ideas that began with Logo in the 1960s and ideas from other current projects such as AgentSheets, Squeak and Alice. It was created to be accessible to children and enjoyable for everyone (Kodu Game Lab Community).

The Microsoft Kodu Game Lab with the power of Microsoft behind it to guide and support it, seems to have experienced rapid spread around the world. It is already used as educational software to teach programming by many schools and educational organizations around the world. Coding Microsoft Kodu is very easy and is done via the keyboard and mouse or through a controller if we are connected to Xbox. The programming process takes place in a threedimensional simulation environment similar to that of Alice, where the user can create many types of games such as speed, strategy, RPGs, adventure, platform, puzzle, and more in a very easy and fun way. Microsoft Kodu's user plans his hero / character to take some action to achieve various goals. (Kodu Game Lab Community) Microsoft Kodu's programming has been freed from the application of many basic programming concepts found in other educational programming environments.

Planning is based on a series of instructions in the form, when something happens then do this (WHEN... DO...). An example of a command written in a descriptive way is: When-see-red-fruit > Do-move-towards-quickly. Of course, the programming in Microsoft Kodu is done visually, by selecting with the mouse or the Xbox controller conditions and actions that will occur when the condition is valid, and adding them to the instruction that will be created. In order for planning to take place, a three-dimensional world must first have been created (with the plethora of tools provided) and objects and characters (from a large number also provided by the environment) must be added to act within it. The behavior of each object-character and the way it interacts with the world are what are determined by programming (Kodu Game Lab Community).

The main menu that appears with the entrance to Microsoft Kodu, where you can choose to create a new world "New empty world", the option of displaying worlds that exist locally on the computer "The world of Kodu" (user-created worlds, worlds from installation of Microsoft Kodu and worlds that have been downloaded locally by the community), the option of displaying worlds that exist in the Microsoft Kodu community "Community" (user worlds if he has shared 
some of them but also other users worlds), the selection of general settings of the environment "Options", "Help" and "Exit Kodu" option (Kodu Game Lab Community).

\section{Microsoft Kodu's basic design environment:}

- With instructions for use in the upper left.

- The bottom menu icon (with various tools and options such as "Home menu", "Play game", "Camera move", "Add or edit characters and objects", "Toolbar", "Ground brush", "Tool for creating hills or valleys", "Tool make the ground level or smooth", "Ground traction tool", "Water add-on / remove / coloring tool", "Deletion tool" and the option "Change world settings").

- The main space where the user designs the world using the tools in the icons menu.

- The area of definition of the instructions that determine the behavior and interaction of the characters and objects of the world.

- The execution window of the created world, where the behavior and interaction of objects and characters of the world is observed, which has been set according to the instructions set by the user.

- The initial menu where the user can save the world he creates, print the code he has created in his world, etc.

\section{WORKING WITH Microsoft KODU LAB GAME}

After several tests with various programs, we decided to install in the computer lab Microsoft Kodu Game Lab, to check how it works and to teach programming through it in third and fifth grade of the 1st Primary School of Niata-Agios Dimitrios in Laconia in Greece. The total number of students in both classes was 15, 7 in the third grade and 8 in the fifth grade.

Before implementing anything else, students had to become familiar with how Microsoft Kodu

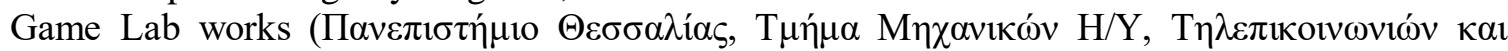
$\Delta$ เ $\tau \dot{\omega} \omega v, 2011)$, and for this reason we have dedicated two teaching hours during which they discovered the potential of this program through small short exercises, working in groups and following collaborative learning and teaching (Bıүкó $\sigma \kappa 1,2008)$. These focused mainly on how to design a three-dimensional environment, the usefulness of design tools and the placement of objects in space. After completing this process, students had enough supplies to begin a completed work.

\section{The objectives are:}

- to learn or exercise in grammatical phenomena such as active and passive voice.

- to check the degree of language proficiency and knowledge.

- to enrich the language course with new technologies.

- to make the lesson more enjoyable. 
The games we created in collaboration with the teachers included repetitive exercises from the Greek language school book of the third grade and fifth grade (Williamson Shaffer, 2006).

\section{Methodology of ReSEARCH}

In the beginning, two games were designed based on the Microsoft Kodu program. This was addressed to the children of third and one for the children of the fifth grade. A series of courses were conducted to familiarize students with Microsoft Kodu's programming environment (Figure 1) and to use it to create simulations and games so that children can explore grammar problems. Microsoft Kodu's environment allows students to create and interact with the objects of a threedimensional world by studying grammar and language issues. At the same time, they discover basic concepts in game planning and design.

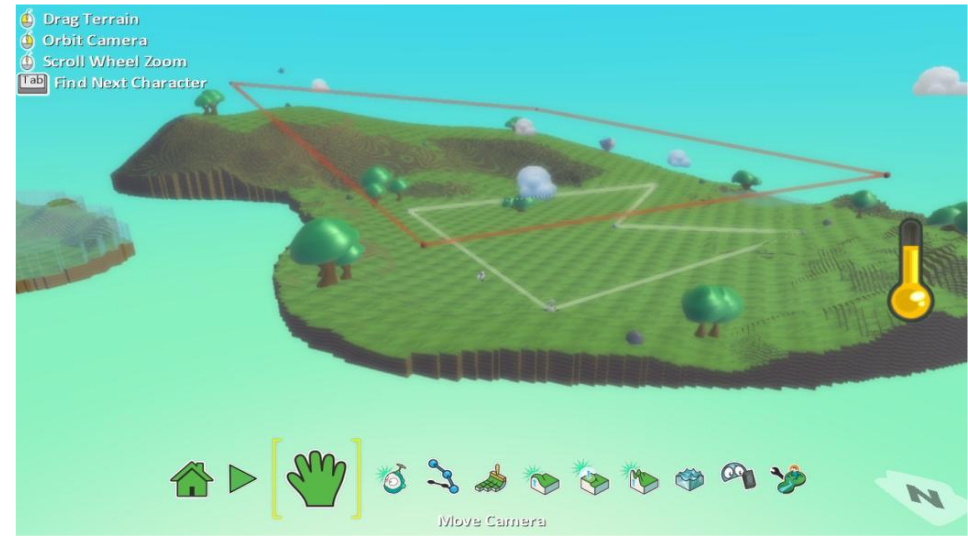

Figure 1: Microsoft Kodu's programming environment

\subsection{Analysis and Design of Research}

At the beginning, there was one lesson per grade where the taught lesson was traditionally given, as provided by the Curriculum. Then, the next lesson was a 15 minute explanation of what they should do, we divided them into groups and they were introduced to the game. Children were asked to interact with the game and try to solve the missions (Figures 2, 3 and 4).

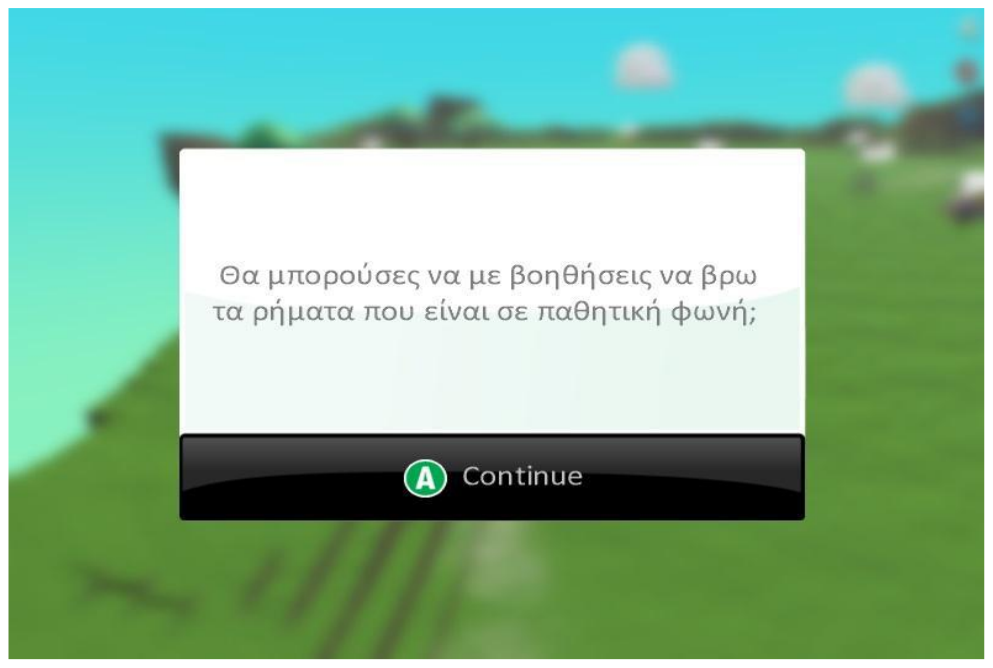

Figure 2 The first exercise-mission: Finding verbs in passive voice 
International Journal of Education (IJE) Vol.8, No.3, September 2020

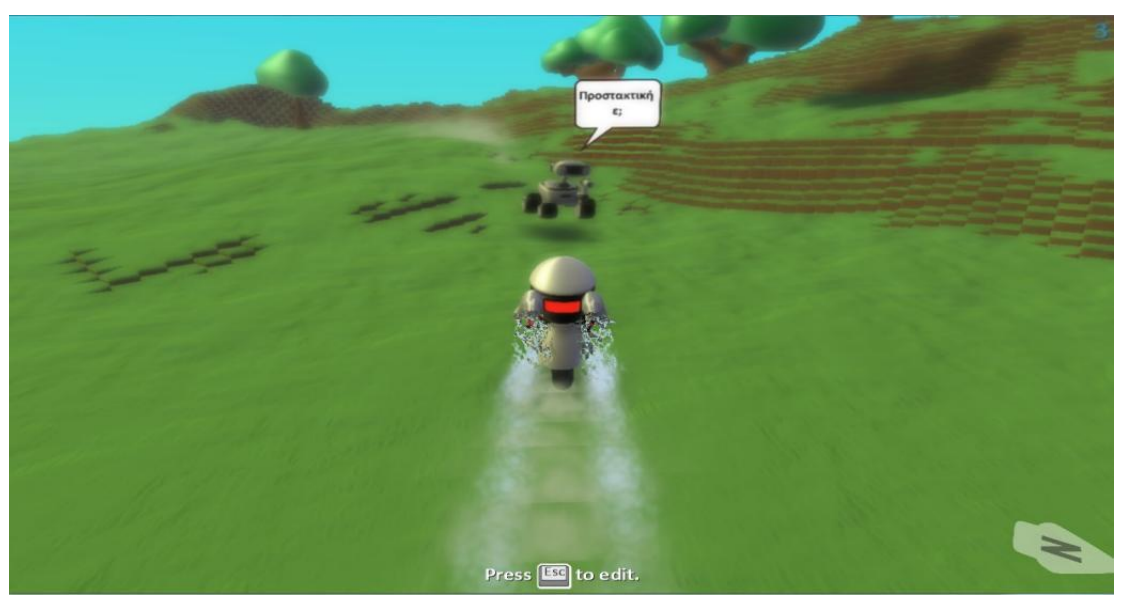

Figure 3 Student-User selects the right answer

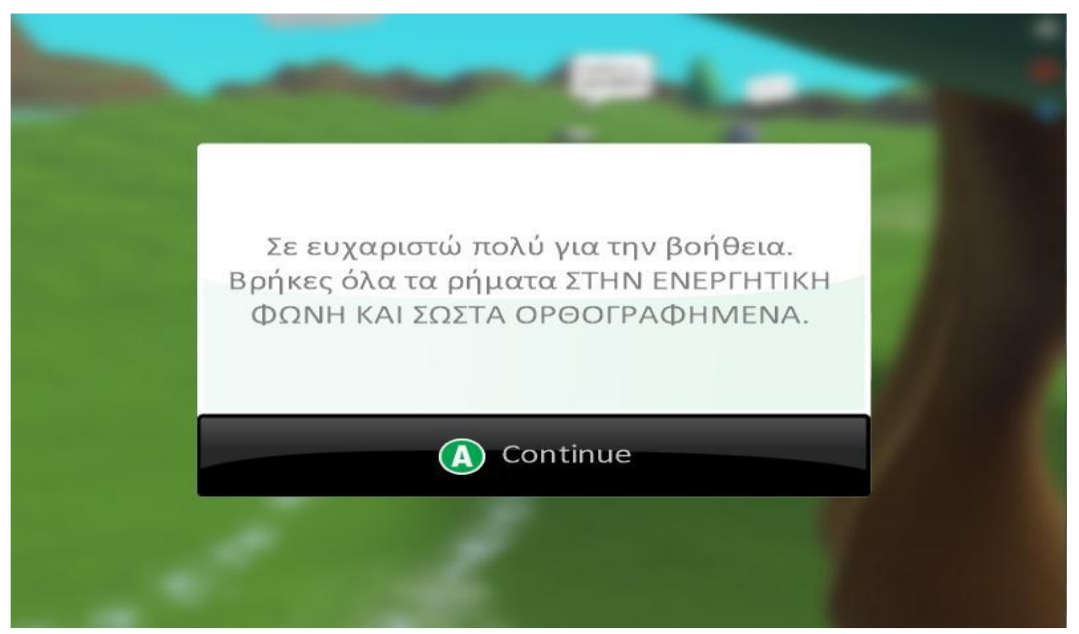

Figure 4 Mission accomplished: Student-user finds all the verbs in active voice

Finally, after the interaction with the game, children had to complete an assessment sheet and record their impressions on it.

\subsection{Results of the Assessment Sheet}

The same assessment sheet was given to both grades and contained four basic questions:

- Is Microsoft Kodu interesting?

- Do you enjoy Microsoft Kodu's environment?

- Do you enjoy grammar lesson through Microsoft Kodu?

- Is Microsoft Kodu difficult in use?

Each student, through five point Likert scale, answered the sheet individually. Specific time was provided by the teachers, immediately after engaging with the software. As research is quantitative, Microsoft Excel was used to process and export its results. 


\subsubsection{Third Grade}

As for the third grade, $65 \%$ of students found it very interesting to extremely interesting compared to $14 \%$ who were indifferent to the game (Figure 5). We already understand that Microsoft Kodu is already showing interest from a significant portion of children. $72 \%$ of the children extremely enjoyed the game environment, the graphics and how the Microsoft Kodu world was made. On the contrary, only $7 \%$ considered it as slightly enjoyable (Figure 6). $65 \%$ of students enjoyed very much the way grammar lesson was conducted (through new technologies). $13 \%$ were rather unpleased with this procedure (Figure 7). 36\% of children deal with some difficulty during game's use but only 14\% faced severe difficulties. However, $29 \%$ of them said it was not difficult at all (Figure 8).

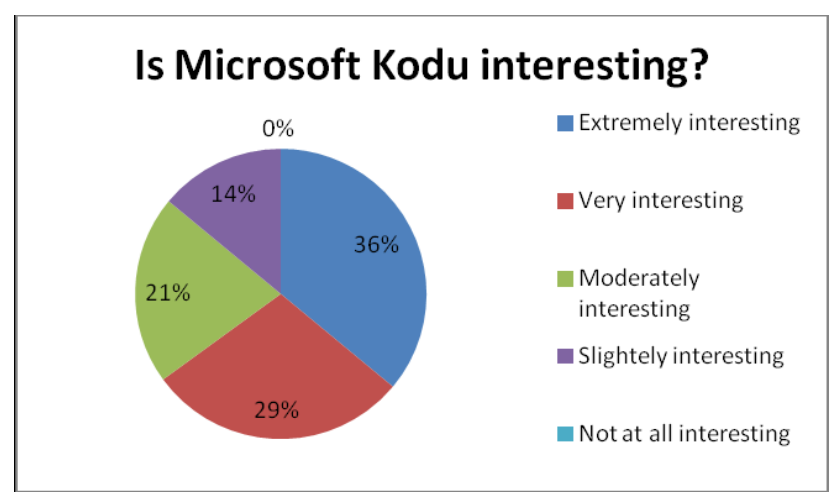

Figure 5 Third grade students' answers to the first question of the assessment sheet

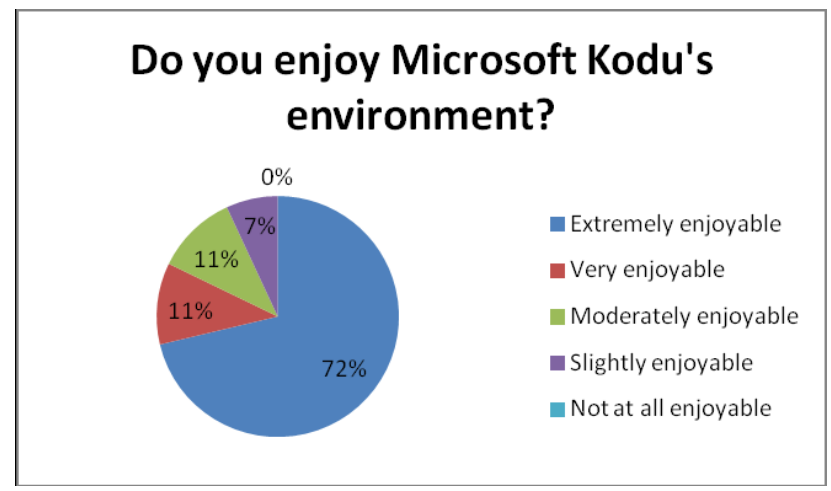

Figure 6 Third grade students' answers to the second question of the assessment sheet

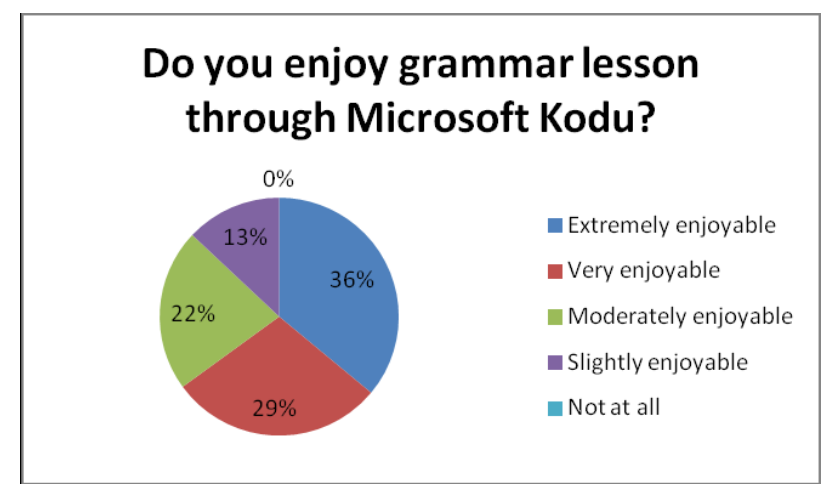

Figure 7 Third grade students' answers to the third question of the assessment sheet 


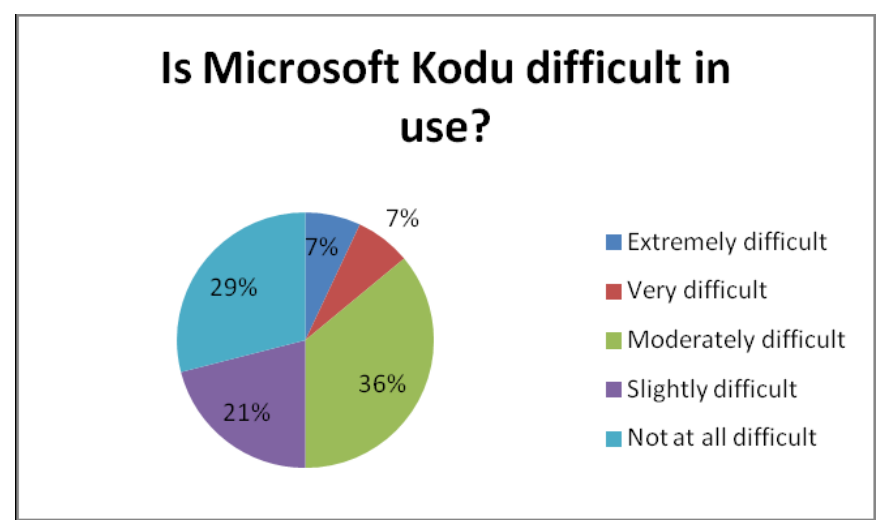

Figure 8 Third grade students' answers to the fourth question of the assessment sheet

\subsubsection{Fifth Grade}

As for the fifth grade, $69 \%$ of students found it very interesting to extremely interesting compared to the $6 \%$ who were indifferent to the game (Figure 9). $63 \%$ of the children enjoyed the game environment, the graphics and how the Microsoft Kodu world was made. On the contrary, $6 \%$ did not enjoy it at all (Figure 10). 56\% of students enjoyed very much the way grammar lesson was conducted (through new technologies). $6 \%$ were rather unpleased with this approach (Figure 11). 31\% of children deal with significant difficulties during game's use but at the same time an equal percent of children did not face any inconvenience (Figure 12).

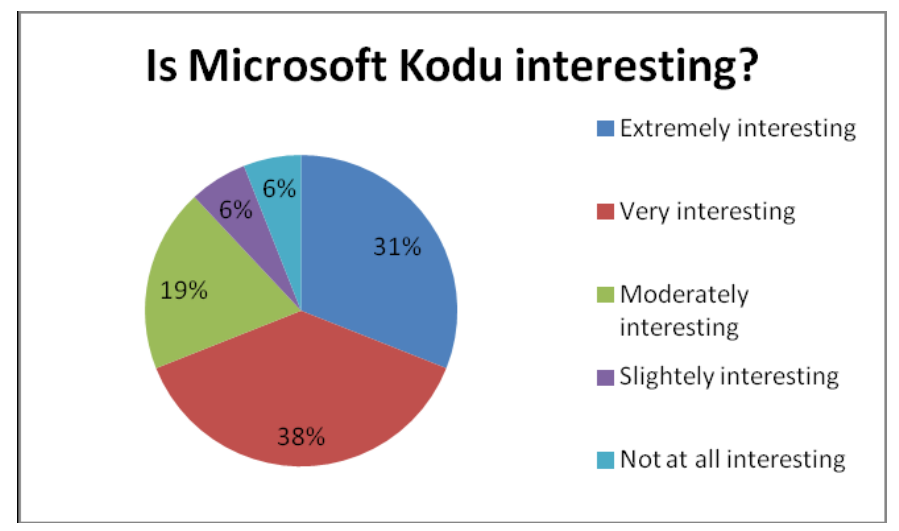

Figure 9 Fifth grade students' answers to the first question of the assessment sheet

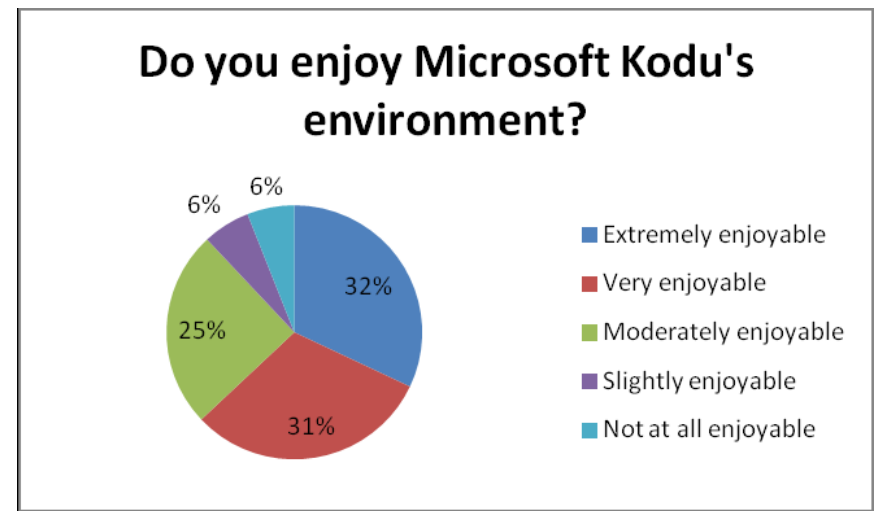

Figure 10 Fifth grade students' answers to the second question of the assessment sheet 


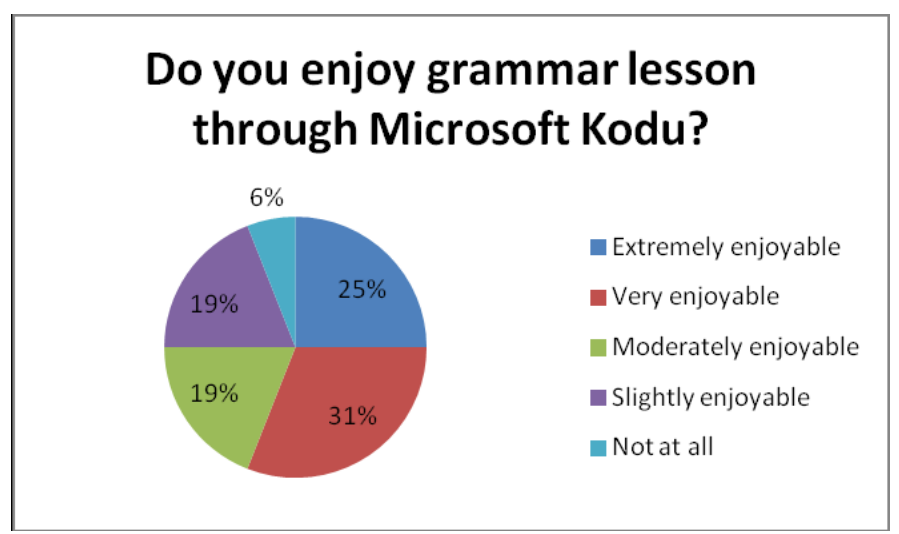

Figure 11 Fifth grade students' answers to the third question of the assessment sheet

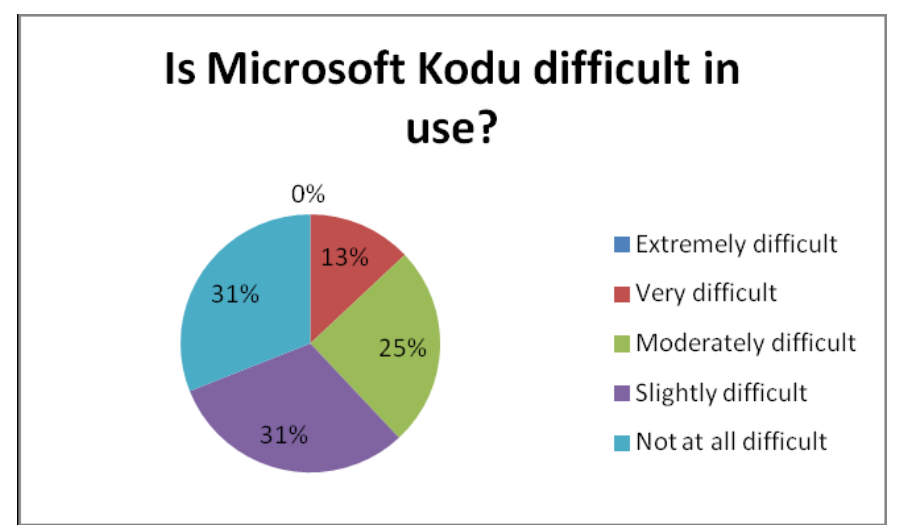

Figure 12 Fifth grade students' answers to the fourth question of the assessment sheet

Overall, the results of the research prove that Microsoft Kodu is interesting and enjoyable software that can be widely used in the teaching of various subjects. Its environment is fun but a prerequisite is that students (regardless of grade and age) have technological literacy and practice new technologies in both school and family environment. Otherwise, they may have difficulty using it and require more teaching time to familiarize students with the software before engaging in exercise-missions. Finally, as shown in Figure 13, fifth grade students seem to be more positive about Microsoft Kodu than third grade students. This is reasonable because fifth grade students are more familiar with new technologies, including software such as Microsoft Kodu as school Curriculum provides them more teaching hours in computer lab than lower grade students.

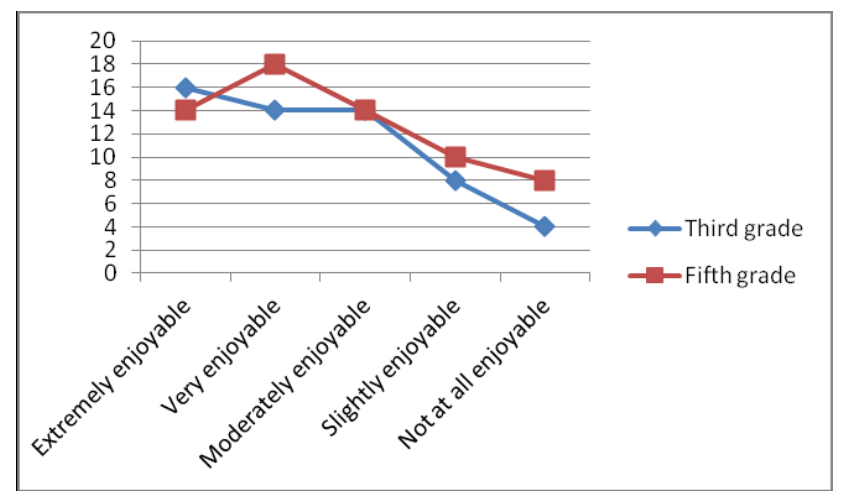

Figure 13 Overall view of third and fifth grade students' opinions on Microsoft Kodu 


\section{Conclusions}

In conclusion, it is worth noticing that, at every stage of teaching, the treatment and the reactions of students during the use of the Microsoft Kodu environment have been enthusiastic and encouraging. In particular, in terms of originality in appearance and ease of understanding and use, the majority of students described it as very easy, very understandable and extremely original. As for the choice of objects as well as the process of planning their behavior, the majority of students described it as very simple. Similarly, during the process of arranging many objects and understanding the use of icons, the students commented that they did not face much difficulty (Egenfeldt-Nielsen, 2007).

We also note that there is a need to make the lesson process more interesting and to adopt new approaches to the concepts that should be taught. Students need to be motivated to participate in school lessons and a way to achieve this is to use new digital media that are considered particularly popular within students and young people.

It is also clear that digital educational games are helping to improve the quality of language teaching. The games created in the context of this research contributed to the strengthening of learning and supported the teaching of the Modern Greek language in Primary School as they are related to the subject and have the characteristics of Curriculum in terms of content, aesthetics and grammar exercises.

In closing, it is good to mention that many of the students after the end of the lesson asked to have some time to play in "the game", describing it as very fun!

\section{REFERENCES}

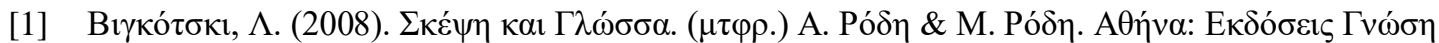

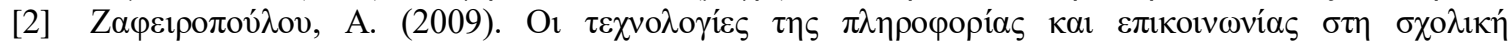

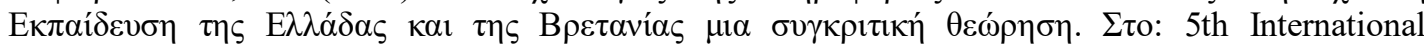
Conference in Open \& Distance Learning

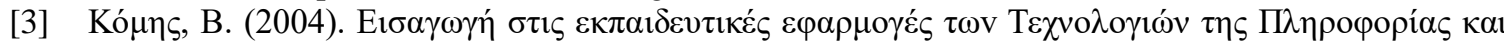

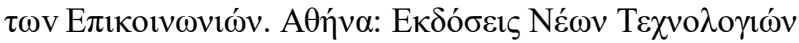

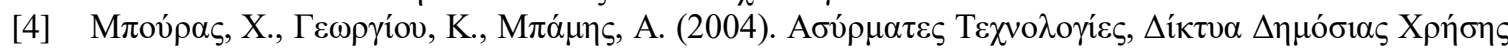

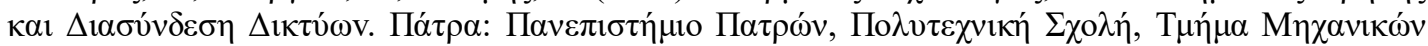

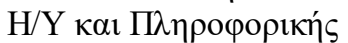

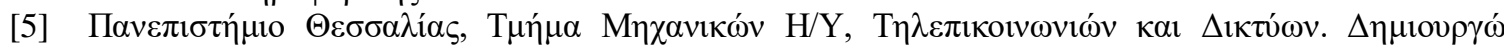

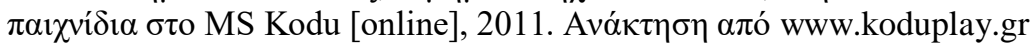

[6] Commission of the European Communities, (2001). Commission Communication to the Council, The European Parliament, The Economic and Social Committee and the Committee of the Regions. Working together for the future of European tourism [online]. Brussels. Available from: http://aei.pitt.edu/5237/1/5237.pdf [accessed 25/06/2020]

[7] Egenfeldt-Nielsen, S. Third Generation Educational Use of Computer Games. Journal of Educational Multimedia and Hypermedia [online]. 16 (3), pp. 263-281, 2007. Available from: https://pdfs.semanticscholar.org/bbdc/33f896d1db93725e59b9f63c8abe3fe5c66e.pdf [accessed 25/06/2020]

[8] Egenfeldt-Nielsen, S., Jonasheider, S. \& Pajares, S. (2008). Understanding Video Games: the essential introduction, New York and London: Routledge Taylor and Francis group

[9] Kodu Game Lab Community [online]. Available from: www.kodugamelab.com [accessed 25/06/2020]

[10] Williamson Shaffer, D. (2006). How computer games help children learn. USA: Palgrave Macmillan. 